\section{AB0434 EARLY EXPERIENCE WITH JAK INHIBITOR PRESCRIBING IN THE UK: RESULTS FROM THE BRITISH SOCIETY FOR RHEUMATOLOGY BIOLOGICS REGISTER FOR RHEUMATOID ARTHRITIS (BSRBR-RA)}

Jennifer Page ${ }^{1}$, Lianne Kearsley-Fleet ${ }^{1}$, Rebecca Davies ${ }^{1}$, Kath Watson $^{1}$, Kimme Hyrich ${ }^{1,2}$, Mark Lunt ${ }^{1} .{ }^{1}$ The University of Manchester, Arthritis Research UK Centre for Epidemiology, Manchester, United Kingdom; ${ }^{2}$ NIHR Manchester BRC, Manchester University NHS Foundation Trust, Manchester, United Kingdom

Background: In 2017 a new class of oral disease modifying anti-rheumatic drugs (DMARDs), janus kinase inhibitors (JAKi), were licensed for rheumatoid arthritis (RA): baricitinib and tofacitinib. In the UK, they are approved for use in patients with high disease activity with or without methotrexate, following failure of conventional synthetic (cs) DMARDs or biologic DMARDs, the latter when rituximab is contraindicated. As a new therapy option, it is currently unclear how and when these drugs are being prescribed in patients with RA.

Objectives: This analysis aims to describe the characteristics of patients starting JAKi and registered with the BSRBR-RA.

Methods: The BSRBR-RA aims to capture exposure and outcome data in patients with RA receiving biologics, biosimilars and targeted synthetic DMARDs. At the start of therapy, demographic and clinical data, including past treatment data, are collected. Characteristics of all patients receiving a JAKi for the first time with data recorded in the BSRBR-RA up to 30/ $11 / 2018$ are described.

Results: To 30/11/2018, 443 patients in the BSRBR-RA have been treated with a JAKi; 374 patients baricitinib and 69 tofacitinib (Table). Twenty-eight percent of baricitinib and $13 \%$ of tofacitinib patients received a JAKi following csDMARDs, with no prior biologic exposure. Of these, $15 \%$ had a prior malignancy history. Of those with prior exposure, the median number of previous biologics was 3 (IQR 2-4) and $52 \%$ had received rituximab. Forty-three percent were receiving concurrent methotrexate.

Conclusion: To date, more patients have been recruited starting baricitinib than tofacitinib, likely owing to the later licensing of tofacitinib. Two groups are emerging with a quarter of patients receiving JAKi immediately after CSDMARDs and a majority as a later stage alternative following multiple biologics. Further recruitment and follow-up patients will allow for analysis of real-world safety and effectiveness, but differences in patient characteristics will need to be considered in any comparative effectiveness analyses.

Characteristics of the first 443 patients in the BSRBR-RA treated with JAKi

\begin{tabular}{|c|c|c|c|}
\hline & $\begin{array}{c}\text { Ever } \\
\text { exposed } \\
{[N=443]}\end{array}$ & $\begin{array}{l}\text { No biologic } \\
\text { exposure } \\
{[\mathrm{N}=112]}\end{array}$ & $\begin{array}{c}\text { Previous biologic } \\
\text { exposure } \\
{[\mathrm{N}=331]}\end{array}$ \\
\hline Baricitinib & $374(84 \%)$ & $103(28 \%)$ & $271(72 \%)$ \\
\hline Tofacitinib & $69(16 \%)$ & $9(13 \%)$ & $60(87 \%)$ \\
\hline Age (years) & $\begin{array}{c}61 \text { (53 to } \\
69)\end{array}$ & $62(51$ to 71$)$ & 61 (53 to 69$)$ \\
\hline Female & $335(76 \%)$ & $81(72 \%)$ & $254(77 \%)$ \\
\hline Disease duration (years) & $12(6$ to 21$)$ & $6(3$ to 15$)$ & 14 (8 to 22$)$ \\
\hline Number of previous biologics & - & - & $3(2$ to 4$)$ \\
\hline No prior biologics & $112(25 \%)$ & $112(100 \%)$ & $0(0 \%)$ \\
\hline 1 prior biologic & $63(14 \%)$ & - & $63(19 \%)$ \\
\hline$\geq 2$ prior biologics & $211(48 \%)$ & - & $211(64 \%)$ \\
\hline Unknown & $57(13 \%)$ & - & $57(17 \%)$ \\
\hline $\begin{array}{l}\text { Type of previous biologic } \\
\text { exposure }\end{array}$ & - & - & - \\
\hline TNF inhibitor & - & - & 248 (91\%) \\
\hline Rituximab & - & - & $143(52 \%)$ \\
\hline Abatacept & - & - & $95(35 \%)$ \\
\hline Tocilizumab & - & - & $139(51 \%)$ \\
\hline Concurrent Methotrexate & $185(43 \%)$ & $51(48 \%)$ & $134(42 \%)$ \\
\hline Concurrent oral steroids & $133(31 \%)$ & $22(21 \%)$ & $111(34 \%)$ \\
\hline Comorbidities $^{\#}$ & - & - & - \\
\hline None & $170(38 \%)$ & $58(52 \%)$ & $112(34 \%)$ \\
\hline 1 comorbidity & $125(28 \%)$ & $25(22 \%)$ & $100(30 \%)$ \\
\hline $2+$ comorbidities & $148(34 \%)$ & $29(26 \%)$ & $119(36 \%)$ \\
\hline Prior Cancer & $38(9 \%)$ & $15(15 \%)$ & $23(7 \%)$ \\
\hline Pulmonary Fibrosis & $11(4 \%)$ & $3(3 \%)$ & $8(4 \%)$ \\
\hline DAS28 & $\begin{array}{l}5.7(5.1 \text { to } \\
6.4)\end{array}$ & 5.6 (5.2 to 6.2$)$ & 5.8 (5.0 to 6.6$)$ \\
\hline HAQ & $\begin{array}{c}2(1.4 \text { to } \\
2.5)\end{array}$ & $1.9(0.9$ to 2.4$)$ & 2.1 (1.5 to 2.6 ) \\
\hline
\end{tabular}

Results presented as $\mathrm{N}(\%)$ or median (IQR). ${ }^{\#}$ Comorbidities - hypertension, ischaemic heart disease, stroke, lung disease (asthma and COPD), renal disease, diabetes, depression, liver disease.
Disclosure of Interests: Jennifer Page: None declared, Lianne KearsleyFleet: None declared, Rebecca Davies: None declared, Kath Watson: None declared, Kimme Hyrich Grant/research support from: Grants to institution: BMS, Pfizer, UCB, Mark Lunt: None declared DOI: 10.1136/annrheumdis-2019-eular.508

\section{AB0435 2 REAL WORLD DATA OF A PATIENT COHORT WITH RHEUMATOID ARTRITIS TREATED WITH JAK/STAT INHIBITORS}

Isabel de la Morena, Juan Alberto Paz Solarte, Diego Bedoya, Pilar Trenor Larraz. Hospital Clinico Universitario de Valencia, Valencia, Spain

Background: We present the real World data of a patient cohort with rheumatoid arthritis (RA) that received one of the two JAK/STAT inhibitors approved by the EMA for this indication.

Objectives: To describe the Real World Data of a patient cohort attending Rheumatology consult of a reference hospital in Valencia with RA diagnosis and that were treated with JAK/STAT inhibitors.

Methods: A descriptive retrospective study was carried out. There were revised medical histories of 28 patients with a RA diagnosis that attended our consults between 2017 and 2018. All 28 patients were JAK/STAT treatment receivers of one of the two JAK/STAT inhibitors approved: Tofacitinib $10 \mathrm{mg}$ oral QD or Bariticinib $4 \mathrm{mg}$ oral QD. There were collected patient baseline demographic data: sex age, BMI, activity disease score measured by DAS28-CRP and visual pain analogue scale for patient's assessment (VAS). In addition, there were collected the previous synthetic(s) and biological (s) DMARD treatments, as well as the associated treatments. Efficacy and security were also analysed. There were assessed serum biochemical variables, among them acute phase reactants such as CRP and and ESR

Results:

The study population consisted in 28 patients with the following distribution:

\begin{tabular}{lcccccc}
\hline M/F & $\begin{array}{c}\text { Mean } \\
\text { age } \\
\text { (years) }\end{array}$ & $\begin{array}{c}\text { BMl } \\
(\mathrm{kg} / \\
\mathrm{m} 2)\end{array}$ & Baricitinib & Tofacitinib & $\begin{array}{c}\text { DAS28/CRP (at } \\
\text { de begining) }\end{array}$ & $\begin{array}{c}\text { Mean } \\
\text { treatment time } \\
\text { (days) }\end{array}$ \\
\hline $12(42 \%) /$ & 58.39 & 30.12 & $\begin{array}{c}9 \\
(32.14 \%)\end{array}$ & $\begin{array}{c}19 \\
(67.85 \%)\end{array}$ & 4.81 & 230.11 \\
$16(58 \%)$ & & & & & \\
\hline
\end{tabular}

With regards to the previous treatments received, we obtained the following results:

\begin{tabular}{lccccccc}
\hline \multicolumn{2}{l}{ Previous DMARDb } & & & \multicolumn{4}{c}{ Previous DMARDc } \\
\hline 3 TB & 2TB & 1TB & Naïve & 3 & 2 & 1 & Naïve \\
\hline 5 & 3 & 10 & 10 & 2 & 9 & 15 & 2 \\
\hline
\end{tabular}

DMARDb: Number of previous biological treatment

DMARDc: Number of synthetic previous treatments

With regards to efficacy, there were collected 6 treatment withdrawals: 1 primary treatment failure (in Tofacitinib Group) and 5 secondary treatment failures ( 1 in Baricitiib Group and 4 in Tofacitinib Group) and the mean treatment duration was 152 days.

Conclusion: Despite the study population was small and the follow-up time was short, we highlight in our patients that both JAK inhibitor alternatives have shown a security and efficacy profile similar to the results shown in pivotal clinical trials. Despite the previous biological treatment failure and obesity are considered as predictors of bad response to treatment, in our cohort did not represent a high risk to treatment failure, it can be an alternative in the same scenary.

Disclosure of Interests: Isabel de la Morena Speakers bureau: Abbvie, Celgene, Pfzier, UCB, Ghebro, Roche, Sanofi, Janssen., Juan Alberto Paz Solarte Employee of: He is working at UCB since December 2018 when the patient recruitment ended., Speakers bureau: Abbvie, Roche, Pfzier, Novartis, Celgene, Amgen, MSD, Janssen, Diego Bedoya: None declared, Pilar Trenor Larraz: None declared

DOI: 10.1136/annrheumdis-2019-eular.8254 